\title{
Seasonal influences on first-episode admission in affective and non-affective psychosis
}

Hallam KT, Berk M, Kader LF, Conus P, Lucas NC, Hasty M, Macneil $\mathrm{CM}, \mathrm{McGorry}$ PD. Seasonal influences on first-episode admission in affective and non-affective psychosis.

Acta Neuropsychiatrica 2006: 18:154-161. (c) Blackwell Munksgaard 2006

Background: Since bipolar affective disorder has been recorded, clinicians treating patients with this disorder have noted the cyclic nature of episodes, particularly an increase in mania in the spring and summer months and depression during winter.

Objective: The aim of this study was to investigate seasonality in symptom onset and service admissions over a period of 10 years in a group of patients $(n=359)$ with first-episode (FE) mania $(n=133)$, FE schizoaffective disorder $(n=49)$ and FE schizophrenia $(n=177)$. Method: Patients were recruited if they were between 15 and 28 years of age and if they resided in the geographical mental health service catchment area. The number of patients experiencing symptom onset and service admission over each month and season was recorded.

Results: In terms of seasonality of time of service admission, the results indicate a high overall seasonality (particularly in men), which was observed in both the schizoaffective and the bipolar groups. In terms of seasonality of symptom onset, the results indicate that seasonality remains in the male bipolar group, but other groups have no seasonal trend.

Conclusions: This provides further evidence that systems mediating the entrainment of biological rhythms to the environment may be more pronounced in BPAD than in schizoaffective disorder and schizophrenia. These results may help facilitate the preparedness of mental heath services for patients at different times of the year.

\author{
Karen T. Hallam ${ }^{1,2}$, Michael Berk ${ }^{1,3}$, \\ Linda F. Kader ${ }^{1}$, Phillipe Conus ${ }^{1,4}$, \\ Nellie C. Lucas ${ }^{1,2}$, Melissa Hasty ${ }^{1}$, \\ Craig M. Macneil', Patrick D. McGorry ${ }^{1}$ \\ ${ }^{1}$ Mania Research Group, ORYGEN Youth Health and \\ ${ }^{2}$ Department of Psychiatry, The University of \\ Melbourne, Parkville, Australia; ${ }^{3}$ Department of \\ Clinical and Biomedical Sciences, Barwon Health; \\ and ${ }^{4}$ Department of Psychiatry, University of \\ Lausanne, Lausanne, Switzerland
}

Keywords: biological rhythm; bipolar disorder; first episode; schizoaffective disorder; schizophrenia; seasonality

Correspondence: Karen T. Hallam, Mania Research Group, ORYGEN Youth Health, and Department of Psychiatry, The University of Melbourne, 35 Poplar Road, Parkville, Victoria 3052, Australia. Tel: +03 9342-2939;

Fax: +03 9387 3003;

E-mail: khallam@unimelb.edu.au

\section{Introduction}

'In the spring, mania, melancholia and epilepsy are apt to occur .... Many diseases regarded as summer affections may also occur in the autumn, such as epilepsy, mania and melancholia' (Hippocrates circa 400 BC)

Since descriptions of bipolar affective disorder (BPAD) have been recorded, professionals treating patients with this disease have noted the seasonal nature of the illness, with a general consensus of increased mania during the spring/summer months and depression during autumn and winter (1). A number of theories have been proposed to explain seasonal recurrence of affective episodes including those on temperature change (2) and seasonal psychosocial stressors (such as vacations and exams) (3). Theories based on changes in light levels and day lengths have received considerable support. These theories are based on the assumption of there being a dual system of circadian entrainment to the 24-h cycle. This system has an intrinsic endogenous circadian pacemaker (the suprachiasmatic nucleus of the hypothalamus), which keeps a cyclic rhythm (generally around $24.5 \mathrm{~h}$ ). The second is an exogenous entrainment system that receives photic (by means of the retinohypothalamic tract) and other regulatory input that resynchronizes this internal rhythm to the 24-h cycle. It is argued that either disruption of this daily 
entrainment or shifts in timing of light exposure may de-synchronize internal circadian rhythms, leading to affective episodes (particularly in BPAD) (1). Sensitivity to environmental changes is best seen in patients with seasonal affective disorder, which responds to bright light therapy, who experience marked depression in winter months (4-8). In a similar manner, researchers have shown abnormalities in hormonal responsiveness (ie melatonin) to bright light in patients with BPAD (912). In patients with bipolar disorder, changes in levels of melatonin are proposed to cause disturbances in the circadian rhythm because it is the primary regulator of the intrinsic circadian pacemakers (13-19). The disturbance in the association between external and internal timekeeping has been postulated to lead to multiple circadian disturbances (20), in particular, a disruption in the sleep-wake cycle, which is a precipitant of manic episodes (21$24)$. The growing understanding of circadian aspects of BPAD has led to the development of treatments that focus on the normalization of circadian rhythms $(25,26)$; however, there has been less focus on the seasonal nature of the illness and the relevance of this to current treatment approaches.

Evidence from a number of large-scale studies provides empirical support for seasonality, with increased mania and mixed episodes in the spring $(27,28)$ and summer months $(29)$. Evidence from studies in the southern hemisphere shows similar trends for an increase in mania in the springsummer (30-33); however, this finding is not universal (34). One finding shows a spring/ summer peak in the depressive phase of the illness (2), whereas others indicate autumn increases (35) or no seasonal variation in depression (34). Further studies reveal a bimodal relationship, with one study on patients with unipolar and bipolar disorders indicating that seasonality clusters into one of two patterns: (a) autumn-winter depression or (b) spring-summer depression (36). In relation to mania specifically, the studies show two clear peaks, first in April (ie northern spring) (over 30\% of manic episodes) and then in September (ie northern autumn) (over 15\%). In terms of gender differences, evidence indicates that seasonality is generally stronger in men than in women, with the latter more likely to display a bimodal distribution of mania and suicide over different seasons $(33,37)$. Finally, Takei et al. (38) have shown seasonality in men and women with mania but only in women with schizophrenia.

In psychotic disorders, some studies provide evidence of seasonality of admissions in firstepisode (FE) (38) and overall schizophrenia (39).
More recent studies have provided mixed support, with one finding no seasonal variation in admissions of patients with either schizophrenia or bipolar mania (40), another finding a summer peak in the onset of acute psychotic states (3) and yet another finding summer peaks that were variable from year to year (29). A confounding factor in many of these studies is that the data on first admission and readmission have rarely been divided. One of the few studies analyzing this indicated that in BPAD, first admission and readmission show a seasonal pattern. However, in schizophrenia, only first admissions show a seasonal peak (41). Alternatively, other studies found seasonality in chronic, not in FE, patients with schizophrenia (42). Combined first and readmission results are also interfered with by chronobiotic (an agent that acts on circadian clocks or timekeeping functioning to alter rhythmicity) effects of medications. For example, a clear seasonality in lithium bioavailability has been shown, which may cause episode variation between treated and untreated patients (37).

Overall, reports vary on whether seasonality is present in patients with BPAD, whether it is more pronounced in FEs or readmissions and whether these same trends are observable in other psychotic illnesses. Illness onset and readmission are not always synchronous and are influenced by service availability and other variables; the former may have greater clinical salience. Differences in seasonality between men and women has been shown in a number of studies, with results indicating differences in distribution and prevalence of seasonal changes between genders in different diagnostic groups; however, no studies have investigated these differences in an FE cohort. The aim of this study was to investigate seasonality in patients using an FE treatment service. The presence of seasonality was investigated for both the onset of the manic or psychotic state and the admission to treatment. Further, seasonality was investigated according to diagnostic status and gender. Based on previous studies, it was predicted that the onset of manic states and admission season in patients with BPAD would display the characteristic increase in the spring-summer months in contrast to the autumn-winter months. It was further hypothesized that patients with an FE of schizophrenia (and schizoaffective disorder) would display a similar seasonal rise in onset of episode and admissions. Finally, based on discrepancies in reports of gender on seasonality, we further tested whether early reports of greater seasonality in men over women was present in patients experiencing their FE of psychosis or mania. 


\section{Method}

\section{Participant details and selection}

This study investigated seasonal variation in illness onset and admission to the treatment program at the Early Psychosis Prevention and Intervention Centre (EPPIC). EPPIC is specifically designed for the treatment of young adults presenting with FE psychotic disorders aged between 15 and 30 years. This report used the data from five large cohort studies conducted at EPPIC between 1989 and 1997, and 2001 and 2005. The demographic details of the majority of the sample have been described elsewhere [see Harris et al. (43)]. As research on seasonality requires studies to be conducted over 12-month periods (to prevent inflated incidence rates in months that are measured more than once), only data for full 12-month periods from each study were used. The pooled data in this study from the five cohorts were drawn from data collected over the period between June 1989 and May 1992 (12 months), February 1993 and January 1994 (12 months), February 1995 and January 1996 (12 months), August 1996 and July 1997 (12 months) and October 2001 and September 2005 (60 months).

The second step in the screening process was to include only participants who met DSM IIIR or DSM IV-TR criteria for schizophrenia, schizoaffective disorder or BPAD. Based on the exclusion by a number of the cohort studies, individuals with other psychosis diagnoses (such as schizophreniform) were excluded from the analysis. Diagnoses were based on the results of the Royal Park Multidiagnostic Instrument for Psychosis [McGorry et al. (44)] (for DSM IIIR) or, in the more recent trial period (2001-2005), the Structured Clinical Interview for DSM-IV (SCID-I/P) (45). Both of these tools have high reliability and validity in diagnosis of psychiatric patients $(44,46,47)$. Owing to the nature of the EPPIC program, all participants had psychotic features (either hallucinations, delusions or both) on entry to the study, thus giving a sample of the more severely manic bipolar probands than would be seen in normal out-patient settings. This sample did not include individuals in the depressive phase of BPAD.

After eliminating patients with other diagnoses (eg brief psychotic disorder, schizophreniform disorder, major depression with psychotic features and substance-induced psychosis), the study consisted of 359 patients between 14 and 30 years of age at entry to service $(\mathrm{M}=22.18, \mathrm{SD}=3.4)$. All patients provided consent for their results to be used in research conducted at the EPPIC. All five trials were approved by the institutional ethics committee and conformed to the National Health and Medical Research Council guidelines on studies involving human subjects.

\section{Geographical and catchment area details}

The city of Melbourne is situated in Victoria, one of the most eastern and southern states of Australia (except Tasmania). Melbourne is located at $-37.81^{\circ}$ latitude and $144.97^{\circ}$ longitude. Seasonal variation in the light-dark cycle differs widely with sunrise to sunset times during midwinter (7:30 a.m. to 5:20 p.m.), while day length is considerably longer in summer (6:15 a.m. to 8:45 p.m. daylight savings time). Average daily temperatures vary between $13^{\circ} \mathrm{C}$ and $26^{\circ} \mathrm{C}$ from midwinter to midsummer. The EPPIC treatment center and in-patient unit are situated just outside Melbourne's central business district (CBD) and services only individuals within the northwestern metropolitan catchment area (within $50 \mathrm{~km}$ of Melbourne CBD). Because of the poorer socioeconomic characteristics of the catchment area, and the consequent limited access to private psychiatric clinics and psychiatrists, most of the cohorts living within this catchment area with mental health issues are treated by the North West Mental Health Service [see Harrigan et al. (48)]. Within this service, all young adults between 15 and 24 years of age who experience FE psychosis are referred to and treated by the EPPIC program.

\section{Onset of illness and admission dates}

Symptom onset was determined by clinical interview and admission interview data from the patient and family. Date of onset of symptoms was considered the timing of a perceptible change in the patient's behaviour. In most files, this included the onset of the first psychotic symptoms such as thought disorder and delusions. In the minority of cases where patients experienced more insidious onset of illness, this was defined from the family report of when they became aware that something was wrong with the patient or noticed a change in the patient's behaviour [eg see Owens and McGorry (49)]. In terms of admission date, the date of admission to the service was extracted from relevant patient files.

\section{Statistical analyses}

Data were categorized into seasons according to the following criteria: summer, December to 
February; autumn, March to May; winter, June to August; and spring, September to November. Monthly data for each diagnostic group were also recorded to investigate peak incidence of new admissions. Seasonality was investigated in two samples of data, both when the patients' manic or psychotic episode begun and when the patient was admitted to the service as either an in-patient or an out-patient. This analysis was performed using non-parametric chi-squared statistics.

For this analysis, data were analyzed as a group (timing of symptom onset in all patients) and then into gender effects (all patients). Following this analysis, the data were split into the subgroups (schizophrenia, schizoaffective disorder and BPAD) and finally gender within subgroups. This same analysis was repeated on the data pertaining to admission dates. The error rate was set at $\alpha=$ .05 for the tests in these two sets of analyses.

\section{Results}

The variations in symptom onset across seasons are presented in Table 1 for schizophrenia, schizoaffective disorder and BPAD by gender.

The results indicate no overall seasonal trend in timing of symptom onset across these diagnostic groups. Further, although there is some indication of an overall trend of seasonality in men, gender effects within diagnostic groups are not evident. The most marked result on analyzing the results in Table 1 is the strong evidence for a significant seasonality in the bipolar group, with patients displaying marked increases in onset of symptoms in spring and lowest incidence in the autumn months.

Figure 1 shows the variation from percentage of expected episodes across the 12-month period. This type of graph develops an expected percent-

Table 1. Symptom onset of mania or psychosis by diagnosis and gender

\begin{tabular}{|c|c|c|c|c|c|c|c|}
\hline $\begin{array}{l}\text { Diagnostic } \\
\text { group }\end{array}$ & Group & $n$ & Summer & Autumn & Winter & Spring & Statistics \\
\hline \multirow[t]{3}{*}{ Overall } & & 359 & 81 & 75 & 99 & 104 & $\chi^{2}(3)=6.493, p=0.090$ \\
\hline & Male & 258 & 56 & 51 & 77 & 74 & $\chi^{2}(3)=7.767, p=0.051$ \\
\hline & Female & 101 & 25 & 24 & 22 & 30 & $\chi^{2}(3)=1.367, p=0.711$ \\
\hline \multirow{3}{*}{ Schizophrenia } & Overall & 177 & 44 & 36 & 53 & 44 & $\chi^{2}(3)=3.271, p=0.352$ \\
\hline & Male & 141 & 33 & 29 & 46 & 33 & $\chi^{2}(3)=4.674, p=0.197$ \\
\hline & Female & 36 & 11 & 7 & 7 & 11 & $\chi^{2}(3)=1.778, p=0.620$ \\
\hline \multirow{3}{*}{ Schizoaffective } & Overall & 49 & 7 & 13 & 16 & 13 & $\chi^{2}(3)=3.490, p=0.322$ \\
\hline & Male & 33 & 5 & 6 & 12 & 10 & $\chi^{2}(3)=3.970, p=0.265$ \\
\hline & Female & 16 & 2 & 7 & 4 & 3 & $\chi^{2}(3)=3.500, p=0.321$ \\
\hline \multirow[t]{3}{*}{ Bipolar } & Overall & 133 & 30 & 26 & 30 & 47 & $\chi^{2}(3)=7.902, p=0.048^{*}$ \\
\hline & Male & 84 & 18 & 16 & 19 & 31 & $\chi^{2}(3)=6.571, p=0.087$ \\
\hline & Female & 49 & 12 & 10 & 11 & 16 & $\chi^{2}(3)=1.694, p=0.638$ \\
\hline
\end{tabular}

*Significant difference at $p=.05$

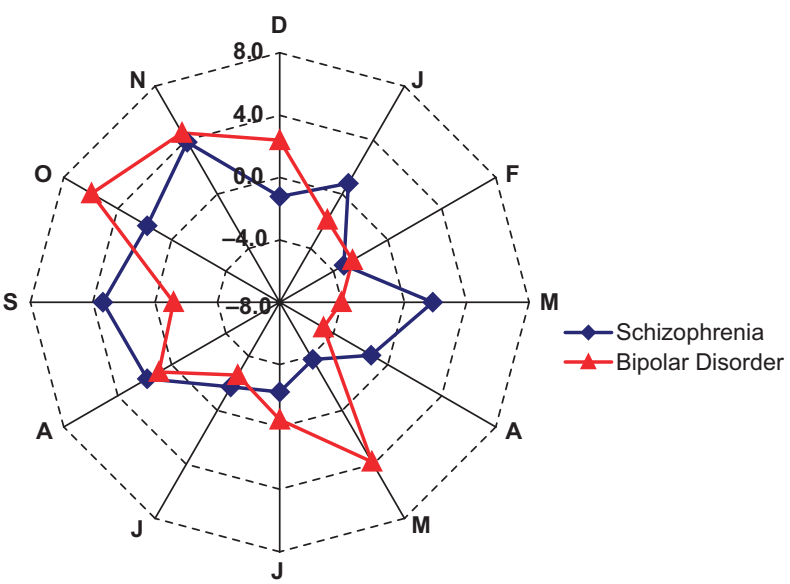

Fig. 1. Radar graph showing monthly percentage difference scores in symptom onset cases (from steady rate of new cases of symptom onset) for patients with BPAD and schizophrenia.

age of episode onsets within a given month based on a uniform pattern. Variations in number of admissions from this pattern are then expressed as a percentage change from this predicted incidence for each of the 12 months for patients with schizophrenia or BPAD. Patients with schizoaffective disorder were not included in this representation because of low sample size.

Figure 1 indicates a considerable peak in the months of August, September and October in the bipolar patient group, consistent with a seasonal variation suggested in Table 1. Although this variation is detected by the seasonal analysis, there is no evidence of acute changes between individual months from the statistical analysis $\left(\chi^{2}=16.684\right.$, $\mathrm{df}=11, p=0.118$ ). In terms of the schizophrenia group, although there are no seasonal effects, there is a significant change in monthly onset across different months $\left(\chi^{2}=20.220, \mathrm{df}=11, p=\right.$ $0.042)$. Figure 1 indicates that there are discrete increases in symptom onset around December, June, July and August, with lower than expected numbers of new patients exhibiting symptoms in January, April and September. Overall, these data indicate that monthly variation in symptom onset in patients with schizophrenia is nonsystematic, in contrast to the more systematic changes observed in patients with bipolar disorder.

For the admission data, the results of the seasonal analysis are presented in Table 2.

The results indicate a significant overall seasonal trend in admissions to the EPPIC treatment service for all groups of psychosis. These results appear to be more robust in men than in women. The strength of this gender effect is amplified in the bipolar group where men had a significant seasonal variation, while women showed a more 
Table 2. Results of seasonality of admission by gender and group

\begin{tabular}{|c|c|c|c|c|c|c|c|}
\hline $\begin{array}{l}\text { Diagnostic } \\
\text { group }\end{array}$ & Group & $n$ & Summer & Autumn & $n$ Winter & r Spring & Statistics \\
\hline \multirow[t]{3}{*}{ Overall } & & 359 & & 71 & 85 & 125 & $\chi_{2}^{2}(3)=19.552, p<0.001^{* *}$ \\
\hline & Male & 258 & & 52 & 62 & 93 & $\chi^{2}(3)=17.938, p<0.001^{* *}$ \\
\hline & Female & 101 & 27 & 19 & 23 & 32 & $\chi^{2}(3)=3.673, p=0.299$ \\
\hline \multirow[t]{3}{*}{ Schizophrenia } & Overall & 177 & 39 & 39 & 38 & 61 & $\chi^{2}(3)=8.469, p=0.037^{*}$ \\
\hline & Male & 141 & 30 & 31 & 33 & 47 & $\chi^{2}(3)=5.355, p=0.148$ \\
\hline & Female & 36 & 9 & 8 & 5 & 14 & $\chi^{2}(3)=4.667, p=0.198$ \\
\hline \multirow[t]{3}{*}{ Schizoaffective } & Overall & 49 & 7 & 7 & 18 & 17 & $\chi^{2}(3)=9.041, p=0.029^{*}$ \\
\hline & Male & 33 & 5 & 5 & 11 & 12 & $\chi^{2}(3)=5.182, p=0.159$ \\
\hline & Female & 16 & 2 & 2 & 7 & 5 & $\chi^{2}(3)=4.500, p=0.212$ \\
\hline \multirow[t]{3}{*}{ Bipolar } & Overall & 133 & 32 & 25 & 29 & 47 & $\chi^{2}(3)=8.323, p=0.040^{*}$ \\
\hline & Male & 84 & 16 & 16 & 18 & 34 & $\chi^{2}(3)=10.857, p=0.013^{*}$ \\
\hline & Female & 49 & 16 & 9 & 11 & 13 & $\chi^{2}(3)=2.184, p=0.535$ \\
\hline
\end{tabular}

*Significant difference at alpha of .05.

**Significant difference at alpha of .01.

consistent presentation over the year. Although this difference in seasonality was strongest in the bipolar group, it was also present in the schizoaffective group. The monthly breakdown of the change from expected percentage of admissions is presented in Fig. 2 for the schizophrenia and bipolar groups.

The results of the radar graph indicate that the peak in EPPIC admissions for BPAD and schizophrenia occur in the late winter (August) and spring months (except September in the bipolar group), with considerably lower rates in the summer months. There is also a strong peak in admissions of patients with bipolar disorder in May, the final month of autumn. More specifically, analysis of the 12-month variation data indicated that there was a very marked variation in admissions in the bipolar group $\left(\chi^{2}(11)=26.789, p=0.005\right)$. Figure 2 indicates that this variation is associated

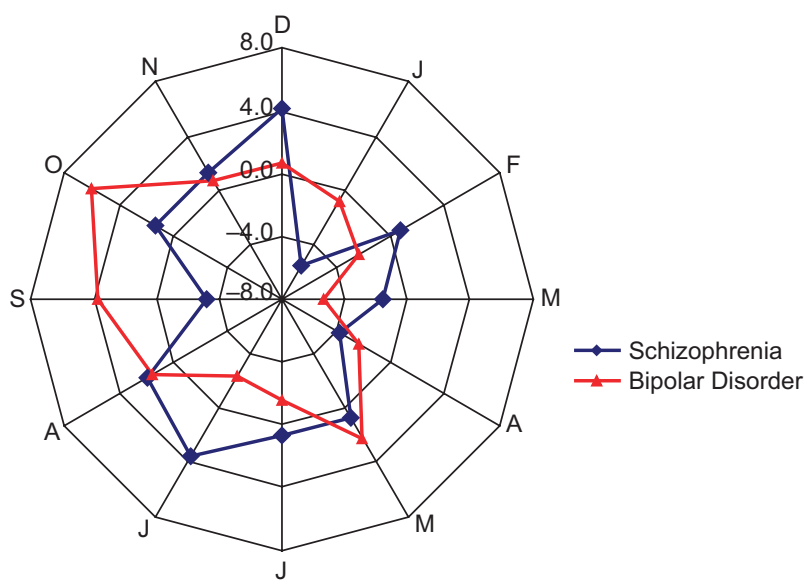

Fig. 2. Radar graph showing monthly percentage difference scores in new admissions (from steady rate) for patients with BPAD and schizophrenia. with the peak in admissions in October, November and December and an acute increase again in May. In the schizophrenia group, only a trend for monthly variations was detected for admission data $\left(\chi^{2}(11)=18.051, p=0.080\right)$. Again, small sample size in the schizoaffective group prevented further analysis. Overall, the peak admissions occurred in September for schizophrenia (11.7\% of yearly schizophrenia admissions), in August for schizoaffective disorder $(14.5 \%)$ and in October for BPAD (14.3\%).

\section{Discussion}

The results of this study indicate that first admissions for psychosis show a seasonal pattern. When split by diagnostic category, the results indicate a seasonal pattern in all three conditions; however, the timing of peaks appears to vary across disorders. More specifically, admissions of patients with schizophrenia peak in spring and those for the schizoaffective group a little earlier in winter and early spring, whereas admissions for bipolar group peak later in the spring and summer periods. The monthly breakdown of these data indicates that the peak incidence of admissions for these disorders occurs in different months according to diagnosis, with earliest onset in August for schizophrenia, in September for schizoaffective disorder and in October for BPAD. The presence of these seasonal effects concurs with the results of the previous studies (30-33).

Notably in the bipolar group, there is a large jump in admissions during May within the autumn-winter transition that is markedly increased compared with admissions immediately preceding and following this month. Further, this autumn-winter increase appears unique to the bipolar group as there is no evidence of increased admissions in the schizophrenia or schizoaffective group. This provides further support for theories that acute episode onset in BPAD may show a bimodal distribution (36) and in mania, a smaller and more concentrated peak in late autumn and a more significant and prolonged increase over spring and summer.

In relation to the hypothesis that onset of symptoms would also show a seasonal variation, the results of the current study were mixed. Unlike Owens and McGorry (49), we did not find an overall seasonal effect but did detect a marked increase in symptom onset in December, June, July and August, in contrast to lower than expected numbers of new patients showing symptom onset in January, April and September. However, 
it is also apparent that there are more patients with schizophrenia who experience symptom onset around the winter months. In terms of the bipolar group, a strong seasonal trend for increased symptom onset in spring is evident.

In relation to the hypothesis of gender differences in seasonality, the results indicate that, overall, men may be more vulnerable to seasonal effects than women. In fact, while men tended to show the characteristic increase in spring admissions, women tended to show a much blunter increase that failed to reach significance. Analysis based on gender by group is somewhat limited because of the small sample of women in relation to overall sample size (eg in the schizophrenia group, 141 of the 177 patients were men). This said, data in both the schizophrenia and the bipolar groups showed a significant seasonal trend for increased spring admissions in men but no significant seasonal effects in women. Gender effects in the schizoaffective group were not evident; however, this group had particularly small numbers.

One of the strengths of the current study is that it investigated only FE admissions, rather than readmissions to hospital. This method eliminates the effect of variability in the number of readmissions in serious psychosis associated with relapse and controls for treatment effects. Theoretically, the other advantage of examining FE psychosis is the absence of chronicity. According to a number of staging (50) and kindling theories (51) of mental illnesses, it is assumed that there are a number of neurobiological changes associated with disease progression that phenomenologically change the symptoms, altering the relative contribution of extrinsic and intrinsic factors. For instance, in patients with BPAD, episode frequency and severity increase as the disease progresses and become less associated with identifiable environmental stressors and therefore more 'intrinsic'. An additional advantage of this study design is the timing of symptom onset and admission to treatment services. This overcomes the flaws of previous studies that only considered admission times as it is acknowledged that in some disorders, a considerable time may elapse between onset of symptoms and clinical presentation (eg schizophrenia), whereas in others, illness state may deteriorate rapidly (ie mania in patients with bipolar disorder).

Elements limiting the generalizability of these results also warrant attention. First, although assessment of onset date was based on multiple sources and was defined with as much preciseness as possible, it is nevertheless retrospectively determined. This may increase the likelihood of error in estimating onset, which could hinder the observation of a seasonality in onset time. Second, admission time, although a valid proxy of variations in illness intensity, is also dependent on various other elements that are not directly related to the disorder itself, which may confound results. Finally, the relatively small sample size limits the power of our findings.

Overall, these data may have implications for service delivery to these populations. In particular, clinicians working with patients with mania may benefit from increased vigilance for manic symptoms around the late winter and spring months. Further, in patients with a seasonal pattern of illness, clinicians may provide more effective treatment with a program that includes components addressing social and biological rhythm regularity. One such program is the interpersonal and social rhythm therapy, which has shown some efficacy in treating patients with BPAD (52-54). It may be useful to investigate whether the patients benefiting from this type of program are also those who display seasonal forms of the illness, hence indicating that the treatment addressed a biological vulnerability in this group. In those patients particularly vulnerable to environmental influences, alterations to the combinations or dose of medications may be particularly useful. Previous studies indicate that some medications such as lithium and valproate (mood stabilizers) have chronobiotic activity (ie assist in normalizing circadian rhythms) $(9,55,56)$. Recent evidence indicates that this chronobiotic effect may be mediated through intracellular glucogen synthase kinase (GSK) $3 \beta$ and clock gene activation $(37,57-$ 61). Ongoing research in both clinical populations and preclinical models [ie animal paradigms of circadian and seasonal rhythms such as sheep and rabbits $(62,63)]$ is required to determine the genetic and molecular basis of these variations in clinical populations. Converging evidence from the chronobiotic activity of mood stabilizers, seasonal variation in their bioavailability and these results indicating the seasonal nature of BPAD in early stages of illness indicate a biological vulnerability in these patients in the system/s that control rhythmicity.

\section{References}

1. Goodwin FK, Jamison KR. Manic-depressive illness. New York: Oxford University Press, 1990.

2. Shapira A, Shiloh R, Potchter O, Hermesh H, Popper M, Weizman A. Admission rates of bipolar depressed patients increase during spring/summer and correlate with maximal environmental temperature. Bipolar Disord 2004;6:90-93.

3. Malhotra S, Varma VK, Misra AK, Das S, Wig NN, SAntosh PJ. Onset of acute psychotic states in India: a 
study of sociodemographic, seasonal and biological factors. Acta Psychiatr Scand 1998;97:125-131.

4. Meesters Y, Jansen JHC, Beersma DGM, Bouhuys AL, VAN DEN HOOFDAKKeR RH. Light therapy for seasonal affective disorder. Br J Psychiatry 1995;166:607-612.

5. Skwerer RG, Jacobsen FM, Duncan CC et al. Neurobiology of seasonal affective disorder and phototherapy. J Biol Rhythms 1988;3:135-154.

6. Thompson C, Stinson D, Smith A. Seasonal affective disorder and season-dependent abnormalities of melatonin suppression by light. Lancet 1990;336:703-706.

7. Timo P, LonnQvist J. Seasonal affective disorder. Lancet 1998;352:1369-1374.

8. Wirz-Justice A, Graw P, Krauchi K et al. Light therapy in seasonal affective disorder is independent of time of day or circadian phase. Arch Gen Psychiatry 1993;50:929-937.

9. Nurnberger JI JR, Adkins S, Lahiri DK et al. Melatonin suppression by light in euthymic bipolar and unipolar patients. Arch Gen Psychiatry 2000;57: 572-579.

10. Nathan PJ, Burrows GD, Norman TR. Melatonin sensitivity to dim white light in affective disorders. Neuropsychopharmacology 1999;21:408-413.

11. Lewy AJ, Nurnberger JI Jr, Wehr TA et al. Supersensitivity to light: possible trait marker for manicdepressive illness. Am J Psychiatry 1985;142:725-727.

12. Lewy AJ, Wehr TA, Goodwin FK, Newsome DA. Manic-depressive patients may be supersensitive to light (Letter). Lancet 1981;1:383-384.

13. Wahlund B, SaAf J, Grahn H, Wetterberg L. Diagnostic subgrouping of depressed patients by principal component analysis and visualized pattern recognition. Psychiatry Res 1998;81:393-401.

14. Kennedy SH, Kutcher SP, Ralevski E, Brown GM. Nocturnal melatonin and $24 \mathrm{~h}$ 6-sulfatoxymelatonin levels in various phases of bipolar affective disorder. Psychiatry Res 1996;63:219-222.

15. BROwN GM. Neuroendocrine probes as biological markers of affective disorders: new directions. Can J Psychiatry 1989;34:819-823.

16. Robertson JM, Tanguay PE. Case study: the use of melatonin in a boy with refractory bipolar disorder. J Am Acad Child Adolesc Psychiatry 1997;36:822-825.

17. Leibenluft E, Feldman-Naim S, Turner EH, Schwartz PJ, Wehr TA. Salivary and plasma measures of dim light melatonin onset (DLMO) in patients with rapid cycling bipolar disorder. Biol Psychiatry 1996; 40:731-735.

18. Wahlund B, Grahn H, SaAf J, Wetterberg L. Affective disorder subtyped by psychomotor symptoms, monoamine oxidase, melatonin and cortisol: identification of patients with latent bipolar disorder. Eur Arch Psychiatry Clin Neurosci 1998;248:215-224.

19. Hallam KT, Olver JS, Norman TR. Melatonin sensitivity to light in monozygotic twins discordant for bipolar I disorder. Aust N Z J Psychiatry 2005; 39:947.

20. Linkowski P, Kerkhofs M, Van Onderbergen A et al. The 24-hour profiles of cortisol, prolactin, and growth hormone secretion in mania. Arch Gen Psychiatry 1994;51:616-624.

21. Riemann D, Voderholzer U, Berger M. Sleep and sleep-wake manipulations in bipolar depression. Neuropsychobiology 2002;45(Suppl. 1):7-12.
22. Wehr TA, SAck DA, Rosenthal NE. Sleep reduction as the final common pathway in the genesis of mania. Am J Psychiatry 1987;144:201-204.

23. WEHr TA. Effects of sleep and wakefulness in depression and mania. In: Montplaisir J, Godbout R, eds. Sleep and biological rhythms. London: Oxford University Press, 1990:42-86.

24. Wenr TA. Sleep loss: a preventable cause of mania and other excited states. J Clin Psychiatry 1989; 50(Suppl.):8-16.

25. Columbo C, Lucca A, Benedetti F, Barbini B, Campori E, Smeraldi E. Total sleep deprivation combined with lithium and light therapy in the treatment of bipolar depression: replication of the main effects and interaction. Psychiatry Res 2000;95:43-53.

26. Wirz-Justice A, Quinto C, Cagochen C, Werth E, Hock C. A rapid-cycling bipolar patient treated with long nights, bedrest and light. Biol Psychiatry 1999; 45:1075-1077.

27. Cassidy F, Carroll BJ. Seasonal variation of mixed and pure episodes of bipolar disorder. J Affect Disord 2002; 68:25-31.

28. Frangos E, Athanassenas G, Tsitourides $\mathrm{S}$ et al. Seasonality of the episodes or recurrent affective psychosis. Possibly prophylactic interventions. J Affect Disord 1980;2:239-247.

29. Clarke M, Moran P, Keogh F et al. Seasonal influences on admissions in schizophrenia and affective disorder in Ireland. Schizophr Res 1998;34:143-149.

30. Mulder RT, Cosgriff JP, Smith AM, Joyce PR. Seasonality of mania in New Zealand. Aust N Z J Psychiatry 1990;24:187-190.

31. Jones I, Hornsby H, Hay D. Seasonality of mania: a Tasmanian study. Aust N Z J Psychiatry 1995;29: 449-453.

32. Sayer HK, Marshall S, Mellsop GW. Mania and seasonality in the southern hemisphere. J Affect Disord 1991;23:151-156.

33. Parker G, Walter S. Seasonal variation in depressive disorders and suicidal deaths in New South Wales. Br J Psychiatry 1982;140:626-632.

34. Daniels BA, Kirkby KC, Mitchell P, Hay D, Mowry B. Seasonal variation in hospital admissions for bipolar disorder, depression and schizophrenia in Tasmania. Acta Psychiatr Scand 2000;102:38-43.

35. Silverstone T, Romans S, Hunt N, McPherson H. Is there a seasonal pattern of relapse in bipolar affective disorders? A dual northern and southern hemisphere cohort study. Br J Psychiatry 1995;167:58-60.

36. Faedda GL, Tondo L, Teicher MH et al. Seasonal mood disorders: patterns of seasonal recurrence in mania and depression. Arch Gen Psychiatry 1993;50: $17-23$.

37. D'Mello DA, McNeil JA, Msibi B. Seasons and bipolar disorder. Ann Clin Psychiatry 1995;7:11-18.

38. Takei N, O’Callaghan E, Sham P, Glover G, Tamura A, Murray R. Seasonality of admissions in the psychoses: effect of diagnosis, sex, and age at onset. Br J Psychiatry 1992;161:506-511.

39. Hare EH, Walter SD. Seasonal variation in admissions of psychiatric patients and its relation to seasonal variation in their births. J Epidemiol Community Health 1978;32:47-52.

40. Partonen T, Lonnqvist J. Seasonal variation in bipolar disorder. Br J Psychiatry 1996;169:641-646. 
41. Clarke M, Moran P, Keogh F et al. Seasonal influences on admissions for affective disorder and schizophrenia in Ireland: a comparison of first and re-admissions. Eur Psychiatry 1999;14:251-255.

42. Strous RD, Pollack S, Robinson D, Sheitman B, Lieberman JA. Seasonal admission patterns in first episode psychosis, chronic schizophrenia, and nonschizophrenic psychoses. J Nerv Ment Dis 2001;189: 642-644.

43. Harris MG, Henry LP, Harrigan SM et al. The relationship between duration of untreated psychosis and outcome: an eight-year prospective study. Schizophr Res 2005;79:85-93.

44. McGorry PD, Singh BS, Copolov DL, Kaplan I, Dossetor CR, van Riel RJ. Royal Park Multidiagnostic Interview for Psychosis: part II. Development, reliability and validity. Schizophr Bull 1990;16: 517-536.

45. First MB, Spitzer RL, Gibbon M, Williams JBW. Structured clinical interview for DSM-IV-TR axis I disorders, research version, patient edition. New York: Biometrics Research, 2002.

46. Zanarini MC, Skodol AE, Bender D et al. The collaborative longitudinal personality disorders study: reliability of axis I and II diagnoses. J Personal Disord 2000;14:291-299.

47. Jackson HJ, McGorry PD, Dudgeon P. Prodromal symptoms of schizophrenia in first-episode psychosis: prevalence and specificity. Compr Psychiatry 1995;37: 241-250.

48. Harrigan SM, McGorry PD, Krstev H. Does treatment delay in first-episode psychosis really matter? Psychol Med 2003;33:97-110.

49. Owens N, McGorry PD. Seasonality of symptom onset in first-episode schizophrenia. Psychol Med 2003; 33:163-167.

50. McGorry PD, Hickie IB, Yung AR, Pantelis C, JACKSON HJ. Clinical staging of psychiatric disorders: a heuristic framework for choosing earlier, safer and more effective interventions. Aust $\mathrm{N}$ Z J Psychiatry 2006;40:616-622.

51. Post RM. Transduction of psychosocial stress into the neurobiology of recurrent affective disorder. Am J Psychiatry 1992;149:999-1010.
52. Frank E, Swartz HA, Kupfer DJ. Interpersonal and social rhythm therapy: managing the chaos of bipolar disorder. Biol Psychiatry 2000;48:593-604.

53. Frank E, Swartz HA. Interpersonal and social rhythm therapy. In: Johnson SL, LeAHY RL, eds. Psychological treatments of bipolar disorder. New York: Guilford Press, 2004:162-183.

54. Miklowitz DJ, Richards JA, George EL et al. Integrated family and individual therapy for bipolar disorder: results of a treatment development study. J Clin Psychiatry 2003;64:182-191.

55. Wirz-Justice A. The effects of lithium on the circadian system. In: Lux HD, Aldenhoff JB, Emrich HM, eds. Basic mechanisms in the action of lithium. Amsterdam, The Netherlands: Excerpta Medica, 1982:183-192.

56. Hallam KT, Olver JS, Horgan JE, McGrath C, NORMAN TR. Low doses of lithium carbonate reduce melatonin light sensitivity in healthy volunteers. Int $\mathbf{J}$ Neuropsychopharmacol 2005;8:255-259.

57. Harwood AJ, Agam G. Search for a common mechanism of mood stabilizers. Biochem Pharmacol 2003; 66:179-189.

58. Inahana E, Akiyama M, Miyakawa K et al. Effect of lithium on the circadian rhythms of locomotor activity and glycogen synthase kinase-3 protein expression in the mouse suprachiasmatic nuclei. Eur J Neurosci 2004; 19:2281-2287.

59. Jope RS. Lithium and GSK-3: one inhibitor, two inhibitory actions, multiple outcomes. Trends Pharmacol Sci 2003;24:441-443.

60. Reppert SM, Weaver DR. Coordination of circadian timing in mammals. Nature 2002;418(6901):935-941.

61. Danion JM, Canguilhem B, Bentz I, Imbs JL, Chaillet G. Long-term lithium treatment does not suppress hibernation in European hamsters. Neuropsychobiology 1990;23:31-37.

62. Kennaway DJ, Rowe SA. Melatonin binding sites and their role in seasonal reproduction. J Reprod Fertil 1995;49(Suppl.):423-435.

63. Allain D, Malpaux B, Puechal F, Thebault RG, De Rochambeau H, Chemineu P. Genetic variability of the pattern of night melatonin blood levels in relation to coat changes development in rabbits. Genet Sel Evol 2004:36:207-216. 